\title{
An Innovation Design Approach for Product Service Systems Based on TRIZ and Function Incentive
}

\author{
Jie Jiang $D^{1},{ }^{1}$ Yan $\mathrm{Li}^{2}{ }^{2}$ Lidan $\mathrm{Li}^{3}$ Changchun $\mathrm{Zhou}^{1}{ }^{1}$ Yuxiang Huo, ${ }^{1}$ and Qian $\mathrm{Li}^{1}$ \\ ${ }^{1}$ College of Environment and Civil Engineering, Chengdu University of Technology, Chengdu 610059, China \\ ${ }^{2}$ College of Mechanical Engineering, Sichuan University, Chengdu 610065, China \\ ${ }^{3}$ Sichuan Jiuzhou Electric Appliance Group Co., Ltd., Mianyang 621000, China \\ Correspondence should be addressed to Jie Jiang; 110991785@qq.com
}

Received 25 January 2021; Revised 22 February 2021; Accepted 2 March 2021; Published 20 March 2021

Academic Editor: Long Wang

Copyright (c) 2021 Jie Jiang et al. This is an open access article distributed under the Creative Commons Attribution License, which permits unrestricted use, distribution, and reproduction in any medium, provided the original work is properly cited.

Good balance between product and service is the key in the innovative design of product service systems (PSS). In this study, the evolution route of the PSS based on Teoriya Resheniya Izobretatelskikh Zadatch ideal final result was provided. The function model of the PSS was constructed according to the service blueprint and function system diagrams. On this basis, an innovation design method of the PSS based on function incentive was established. The function incentive strategies included function synergy, function supplement, and function substitution. Finally, the PSS design process of agricultural machinery based on computer-aided innovation platform was analyzed to verify this method.

\section{Introduction}

Product service systems (PSS) originated in the 1990s. The primary goal of PSS is to help manufacturing enterprises focus on the integration of physical products and behavioral services to meet customers' needs instead of only producing and selling physical products [1]. It can satisfy customers' needs more effectively with less environmental damage than traditional production and consumption models. With dwindling natural resources and increasingly serious environmental pollution, many countries and enterprises have realized the importance of reducing the usage of resources and improving environmental protection. Hence, their ultimate goal is to design and manufacture products that can maximize energy and reduce emissions and, at the same time, meet customers' needs. For this reason, PSS have gradually received attention and have been under development in various countries since the 21 st century.

The introduction of service into a product created new development opportunities for manufacturing enterprises and improved the diversity and competitiveness of design solutions. With the continued integration of services and products, determining how to provide customers with diverse and practical solutions has become a challenge. Owing to the unique characteristics of services-intangibility, timeliness, production, and consumption at the same time [2] - the design process of PSS is more complex and innovative than a single product or a singleservice design. By integrating the design of a product and a service, a growing number of PSS design solutions have been generated to meet customers' diverse needs. PSS design should begin with the design of the function [3]. Clarifying the functional interaction between product and service is the essential stage in PSS design.

With the growing amount of research on PSS, mainstream studies were mainly divided into three aspects. (1) The product-oriented design methodology involves the integration and coordination of a service and a product in the whole life cycle of an existing product to obtain the PSS solution $[4,5]$. (2) The service-oriented design methodology explores the needs of various stakeholders in the PSS, a PSS design framework was constructed, and various contacts in the PSS framework were designed [6-8]. (3) Parallel product-and-service design methodology is the equal interaction between a product and a service in PSS design to meet customers' needs $[9,10]$. However, from the practical 
perspective, further studies are needed to address two issues. (1) Avoiding excessive pursuit of service maximization reduces resource consumption but ignores current production and service capacity of manufacturers and service providers, respectively. (2) The design process should be shortened, and the evolution capability should be improved. Therefore, PSS needs to evolve not only in response to changes in market demands but also before potential market demands are discovered. Through the change and reconstruction of PSS, a new design method can be formed. Therefore, the research direction is to use existing product innovation design methods and theories (Teoriya Resheniya Izobretatelskikh Zadatch (TRIZ), Quality Function Deployment (QFD), Design Structure Matrix, etc.) to carry out functional design to the internal system of the PSS and to find the best balance state between product and service.

Recent studies investigated the promising methodology called TRIZ, which is a Russian acronym for "Theory of Inventive Problem Solving." TRIZ is as a set of analytical tools that detect contradictions in the problem-solving process by eliminating or attenuating conflicts [11] and generating innovation [12]. As a structured innovation design method, TRIZ has been applied in PSS design. Lee et al. proposed a generic and systematic service design method with a customer-centric and adductive reasoning logic based on TRIZ; the design ontology was constructed on the basis of 40 principles of TRIZ [13]. Wang and Zhang proposed the product emotional intention to elaborate the invention principle of the product surface structure and functional technology based on TRIZ, and the explanation of the improvement was put forward on the basis of further contradiction analysis [14]. Wang et al. used TRIZ to eliminate the contradiction among these service design requirements and the TRIZ innovation principles as the service resolution in the problem resolution phase [15]. Song and Sakao proposed a design framework with a design process by using different methods in which TRIZ was employed to solve design conflicts [16]. Yang and Xing proposed an eco-innovative method by using TRIZ to design an eco-leasing PSS [17]. Chen and Liu proposed a substancefield model grounded on results from system layer analysis maps, aiming to obtain innovative and improved low-carbon PSS ideas [18]. The analysis of the literature suggested that TRIZ could be effectively applied to PSS design.

QFD method and its adaptation to PSS development (QFD for PSS) is a customer-demand-oriented product design planning method, which was widely considered the optimization tool for product design planning. Haber and Fargnoli analyzed customers' demands by using the Kano model and transformed it into receiver state parameters [19]. Fuzzy analytic hierarchy process was used to evaluate the parameters and inherent uncertainties. Haber et al. proposed a method based on the synergy of QFD for PSS, Axiomatic Design (AD), and Service Blueprint [20]. By using the method, the complexity of meeting requirements in PSS design was reduced, the potential of PSS to meet market demands was maintained, and the risk of overdesign and design conflicts was reduced. Haber and Fargnoli proposed a QFD for PSS method and network analysis process method based on market demand and customer demand analysis to evaluate the interaction between product and service elements to elect customer needs and expectations [21].

Design structure matrix (DSM) is a common method to model systems in matrix form in product innovation design. Sakao et al. aimed at custom PSS, in which the interaction between service elements was considered and reflected in the DSM, to obtain service modules [22]. Lee and Abuali proposed an operable innovative design method based on creative tools such as design structure matrix, spatial mapping, and QFD [23]. Son et al. proposed a technology evolution method based on DSM to facilitate collaborative design among multiple stakeholders [24].

In this study, a PSS evolution curve was established by adopting TRIZ, and an interactive function model of the product and service was proposed using the PSS blueprint. The function incentive strategies were provided to achieve a PSS conceptual design. Through the selection and evaluation of conceptual design solutions, the PSS innovation design was finally generated. In addition, the PSS design module was realized in the prototype system, which was developed by our research group to assist in PSS design.

\section{PSS Evolution Routes Based on the Ideal Final Result of TRIZ}

In this study, PSS is defined as a balanced production system with appropriate proportion between products and services and generally optimized in the whole life cycle service of a product. In the PSS, the relationship between a product and a service is inseparable and interactive. Product is a platform that provides service, whereas service can create value without using materials. Determining how to find the balance between products and services to reduce material flow, to maximize resources, and to protect the environment is the research goal of this study. As the most basic element of conceptual design, function runs through all stages of conceptual design. Starting with function, this study seeks the interactive balance between product function and service function in the conceptual design stage. Hence, PSS innovative design can be linked with customer demands from the very beginning and eliminates the limitations of looking only at product, structure, and technical carrier.

The Ideal Final Result (IFR) of TRIZ [10] refers to the ideal solution that can eliminate the defects of the existing system while maintaining its advantages. The direction of the ideal solution is clearly defined to ensure that the system can always move forward in the process of problem solving. The disadvantage of not having a target in traditional innovative design methods can be avoided, and the efficiency of the innovative design can be improved. The important issue in this technical system is how to realize the function more scientifically rather than the system itself. Idealized improvement of this system is maximizing useful functions and minimizing harmful functions.

The IFR of TRIZ sets a series of ideal models at the beginning of problem solving. The ideal model contains all the elements involved in the problem, such as the ideal system, ideal process, ideal resources, ideal method, ideal 
machine, and ideal materials. The final idealized state of the PSS is an ideal system. The system has no entity, no material, and no energy consumption, but it can achieve all required functions. The parameters that measure the idealization degree of the system are named as the idealization level. The TRIZ idealized level can be calculated as follows:

$$
I=\frac{\sum \mathrm{UF}}{\sum \mathrm{HF}}
$$

Here, I represents the idealized level, $\sum$ UF represents the sum of useful functions, and $\sum H F$ represents the sum of harmful functions. According to the IFR of TRIZ, the idealization level is as follows:

$$
I=\frac{\sum \mathrm{UF}}{\left(\sum \text { cost }+\sum \text { consumption }\right)} .
$$

Here, I represents the idealized level, $\sum$ UF represents the useful function of the PSS, $\sum$ cost represents the total cost consumed by the PSS, and $\sum$ consumption represents the total consumption to the environment. From formula (2), the idealized level of the PSS is directly proportional to useful functions. However, the idealized level of the PSS is inversely proportional to the total cost of consumption and the total consumption of the environment. The PSS design aims to increase the idealized level. According to formula (2), the evolution route of the PSS has the following states:

(1) Increase useful functions: service provides product life cycle benefits and increases useful functions of the PSS. In this evolutionary route, manufacturers change the single physical product form into a diversified product and service form. The product not only addresses customers' demands but also adds a range of services around the physical product to sustain and extend customers' requirements.

(2) Reduce costs: maximizing the efficiency of the physical product is the purpose of this route. In this evolutionary route, manufacturers try to reduce the amount of the physical product to reduce costs. Through rational use and distribution of the physical products, previously products owned by customers can be transformed into customer leasing and sharing.

(3) Reduce environmental consumption: service provides the result directly to customers. Manufacturers focus more on what the physical product can offer, but less on how to achieve it. As much as possible, tangible products are no longer needed, and customers' needs can be achieved in the form of service.

Figure 1 shows the evolution route of the PSS based on the IFR of TRIZ.

\section{PSS Function Representation and Incentive Strategies}

According to Umeda et al. [25], the function of the PSS was defined as a series of product behavior or service behavior descriptions from the perspective of customers. According to this definition, PSS functions are expressed as a series of actions in the form of "what to do."

3.1. PSS Function Modeling. Considering the heterogeneity and interactivity of service and product functions, an effective way is needed to represent the function interaction model of the product and the service in PSS design. A function representation method including the interactive relationship between the product and service was established according to the service blueprint method [26] and the system function diagram [27], which was called the PSS function blueprint method.

In this study, three lines were proposed to divide the whole PSS into four different function areas. The function model boundary was expanded from only the physical product to include the interaction of the customer, product, and service. The three dividing lines of the PSS are product service line, product use line, and service visualization line. First, the whole PSS function blueprint was divided into product function domain and service function domain by the product service line. The division describes the interaction between the product and the service. The product function domain contained the function set of the physical product, whereas the service function domain contained the function set of the intangible service. Second, the product use line divided the product function domain into product use domain and product management domain. The product use domain contained the primary function set that the physical product must have in the use process. The product management domain contained the support function set that can support the physical product to complete its essential functions through software during usage. The relationship between product function domain and product management domain can be represented by the input/output energy flow based on the system function diagram. The product use line describes the interaction between the hardware function and the software function during usage of the physical product. Finally, the service visualization line divided the service function domain into visual service domain and invisible service domain. The visual service domain contained the service function set that customers perceived and engaged with directly. By contrast, the invisible service domain contained the background service function set that customers cannot realize and can only obtain indirectly. The relationship between these two functions was represented by the input and output service flow based on the function system diagram, and the service visualization line described the interaction between the service that customers can directly perceive. Figure 2 depicts four domains of the PSS, as well as the standardized representation of different function types and input/output flow. The thick solid line represents the product service line; the thick dashed line represents the product use line; the thick dotted line represents the visual service line; and the thin solid/dashed line with an arrow represents the input/output flow between functions. 


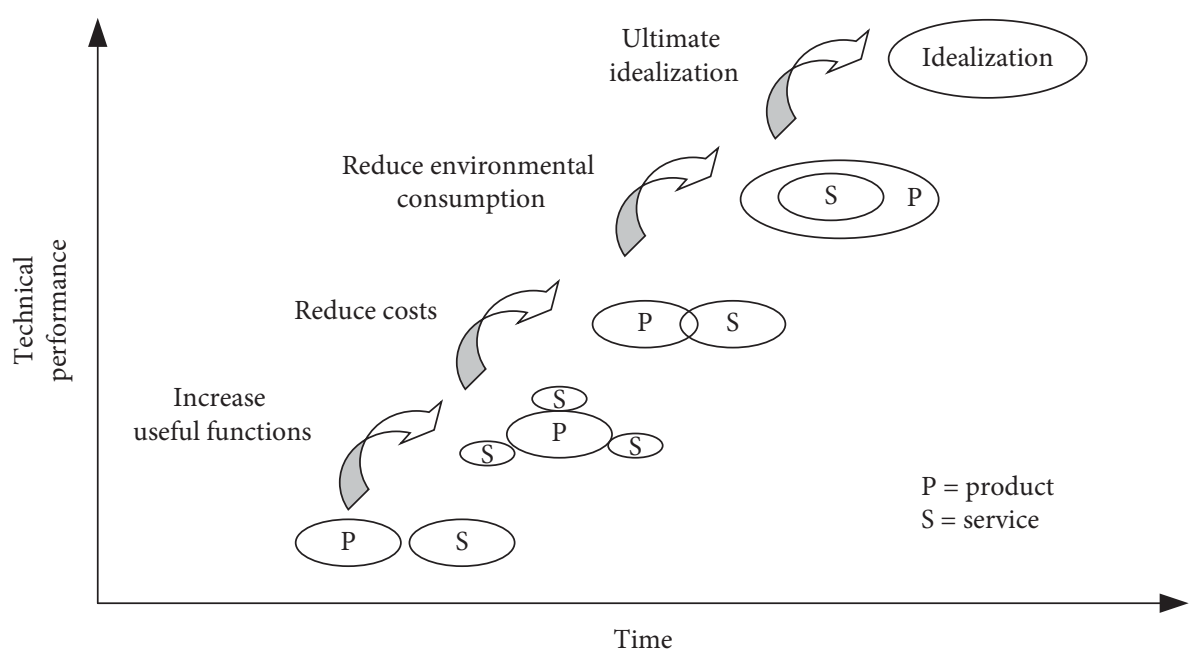

FIGURE 1: PSS evolution route.

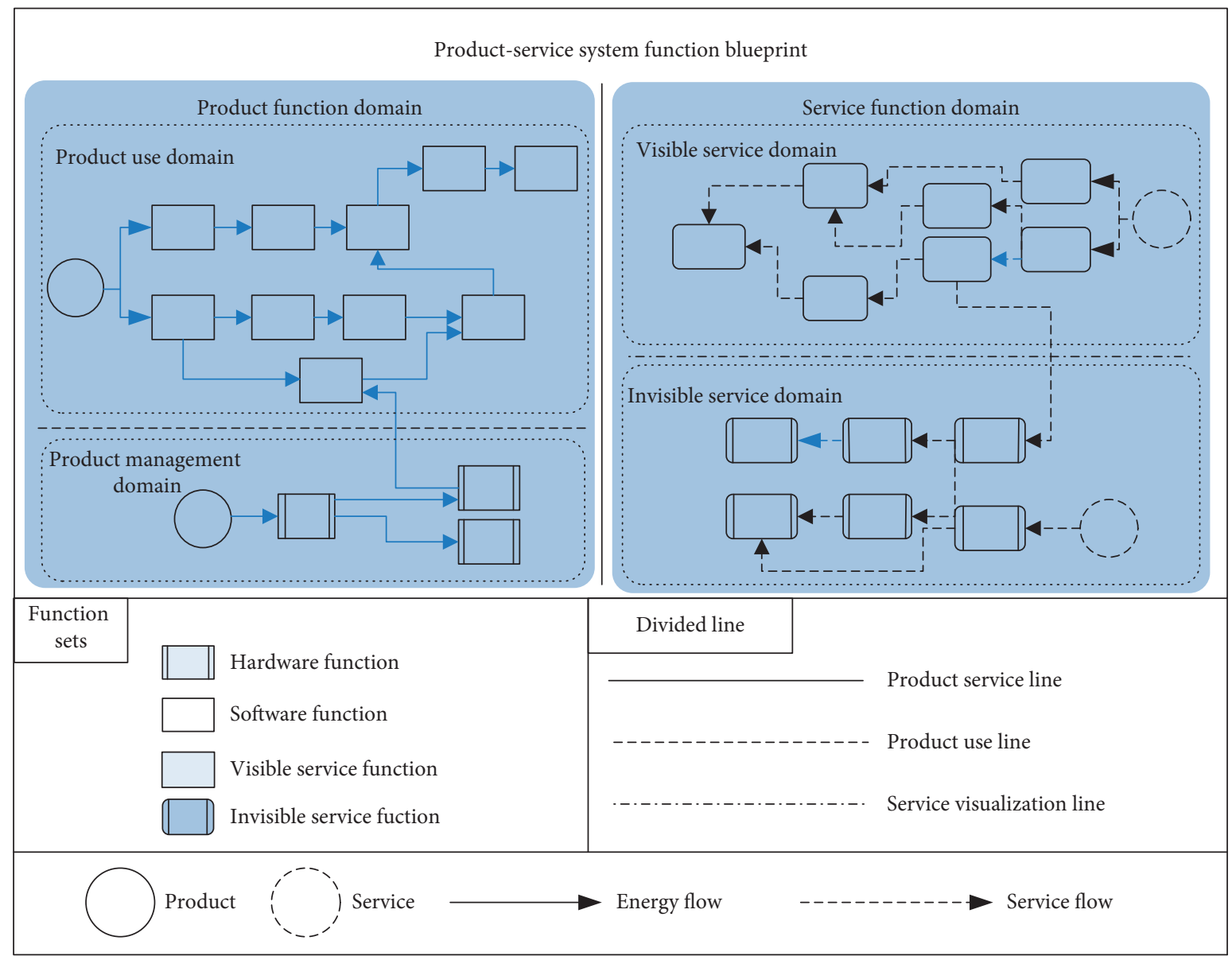

FIGURE 2: PSS function modeling.

3.2. Function Incentive Strategies of PSS. In this study, function incentive strategies under each evolution route of the PSS based on the IFR of TRIZ were proposed, and the innovative design under different routes was realized.
3.2.1. Synergetic Innovation. According to the initial state of the PSS evolution route, the initial evolution direction of the PSS was to increase its useful function by providing additional services for the physical product in the product life 
cycle. Under this evolutionary route, the function incentive strategy was synergetic innovation. Synergetic innovation retained the original excellent characteristics of the existing product. Moreover, it added better functional characteristics after introducing service functions. Take the remote technical support provided by Lenovo, for example. The "maintenance function" in the visual service domain and the "Internet function" in the product use domain worked in coordination with each other. Customers made a corresponding remote service reservation via e-mail or app. In turn, technicians can directly troubleshoot software problems, solve technical problems remotely, and restore hard disk data through the network. Therefore, synergistic innovation tapped the potential functions of the PSS. In addition, it can open new market demand and improve the benefit of an existing product. Ultimately, it can increase useful functions of the PSS.

3.2.2. Supplement Innovation. According to the intermediate state of the PSS evolution route, the evolution direction of the PSS was to change a physical product into a service platform, and its purpose was to optimize usage efficiency. In this evolutionary route, the function incentive strategy was the supplement innovation. Traditional product functions cannot fulfill customers' requirements, and they cannot be further improved due to their technical limitations. Service functions were introduced to supplement product function. For example, traditional medical diagnosis only relied on doctors' previous diagnoses. Hence, different doctors give different conclusions. To address this limitation, GE Medical established an automatic medical support center. The "data interaction" in the invisible service domain and the "cause diagnosis" in the product use domain supplemented each other. Patient diagnosis results were fed back to the GE Medical online center. Through the big medical data system, similar electronic medical records can be retrieved, diagnosis and treatment modes of different doctors can be mined, complementary and interactive diagnosis for patients can be made, and traditional medical devices can be transformed into this platform to provide optimized medical services. Therefore, the service supplement product changed the potential form of the PSS, made the configuration of resources reasonable, and improved the usage efficiency of the physical product to achieve the goal of reducing the PSS cost.

3.2.3. Substitution Innovation. According to the final state of the evolution route, the evolution direction of the PSS was to provide the final result by providing direct service. In this evolutionary route, the function incentive strategy was the substitution innovation. Service functions not only met customers' needs but were also provided with the support of the physical product. For example, iCloud adopted a new way to store and access local files on the basis of network cloud technology. By providing each customer with a cloud terminal, the synchronization and push of information can be realized. iCloud avoided the hard disk drive purchase cost, which shortened the operation cycle and reduced consumption of resources. Therefore, according to substitution innovation, customers can obtain the result of the product directly without owning or purchasing the material form of the product, thus reducing environmental consumption.

\section{PSS Innovation Design}

In this study, the innovation design method of the PSS was systematically realized by different evolution routes. The function model of PSS was proposed, and the incentive strategies were established.

4.1. PSS Innovation Design Process. Figure 3 shows the innovative design process model of the PSS. The design process model includes the following main modules:

4.1.1. Function Modeling Module. In this module, stakeholders of an existing product were analyzed, and the functions of the product were deconstructed. Product functions and service functions were extracted and entered. The PSS function blueprint was constructed according to the function components and stakeholders. The interaction between product and service functions as well as the relationship between different stakeholders and the product/ service was clarified in the PSS.

4.1.2. Evolution Route Selection Module. Designers obtained different customers' requirements through market survey, and the evolution route of the PSS was selected according to these requirements. The selected evolutionary route assisted the designer in clarifying the direction of the PSS innovation design.

4.1.3. Function Incentive Strategy Module. From the selected evolutionary route, the function components were analyzed according to the PSS function blueprint. The multiple possible function results were obtained through the function incentive strategy to obtain the corresponding original design solutions of the PSS.

4.1.4. Design Solution Generation and Evaluation Module. The original PSS solutions were evaluated on the basis of customers' needs. If the market demand and customer demand were not satisfied, then further evolution route and other function incentive strategies were chosen. If the market demand and customer demand were met, then the original PSS solutions were translated into the detailed PSS innovation design solutions with the help of existing knowledge resources. The detailed PSS innovation design solutions were evaluated and optimized according to the manufacturing cost, market condition, and the actual situation of the enterprise. A detailed PSS design solution with better innovation, practicality, and reliability was proposed.

4.2. PSS Innovation Design Based on CAIP 3.0. Computer-Aided Innovation Platform (CAIP 3.0) is an innovative design system. It converges cognitive science, 


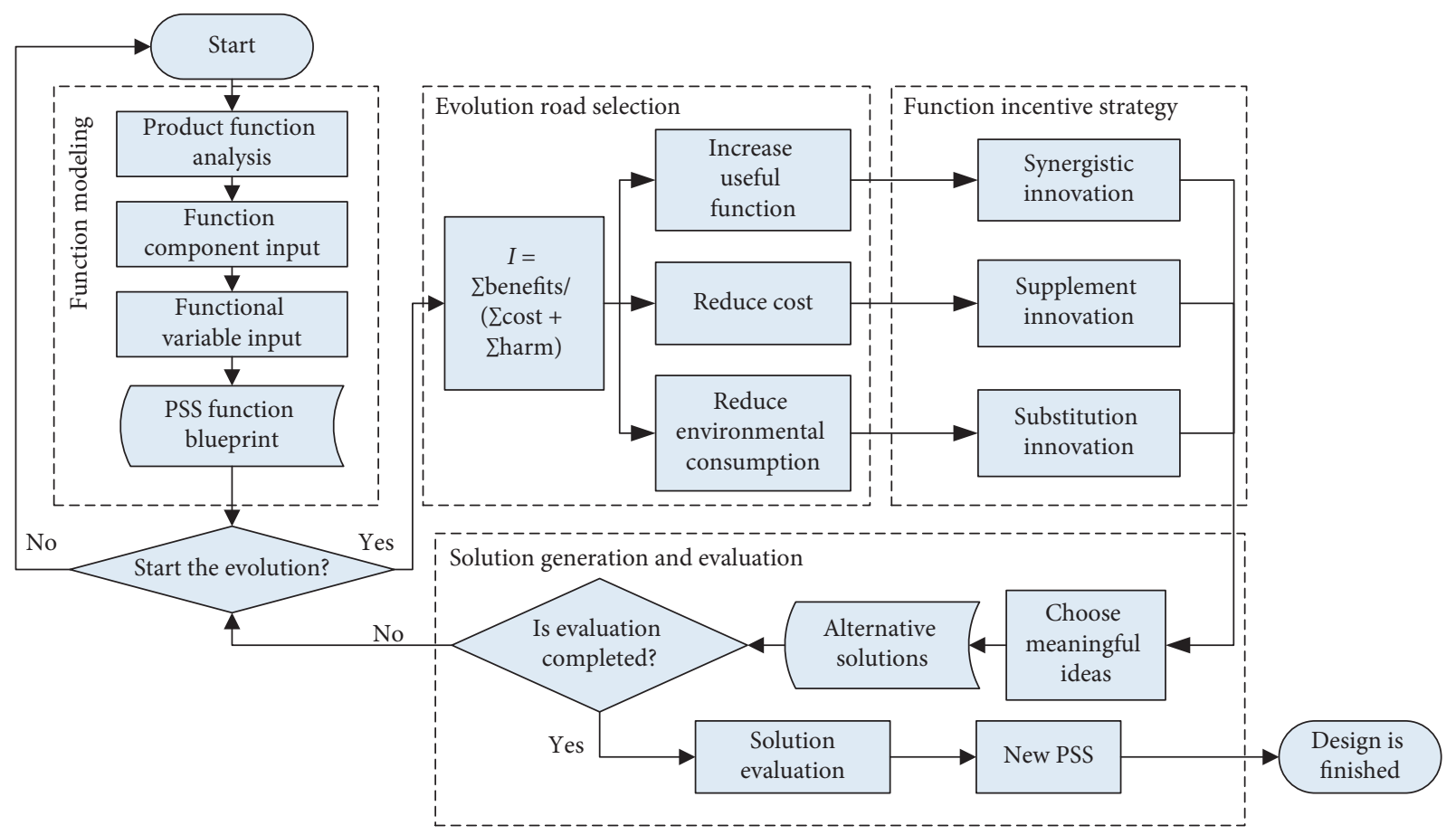

FIgURE 3: PSS innovation design process.

information technology, innovation design theory, and methodology to assist designers in creative design through the interaction of design process and knowledge base. The main development tools and running environment of CAIP 3.0 include Java, Eclipse, Microsoft Access, AWT, Swing, and Eclipse GEF. The development language is JAVA, and the integrated development environment is Eclipse. The background database management system is Microsoft Access. The central technology of the system interface is AWT and Swing. The graphical editing framework is Eclipse GEF. The CAIP 3.0 system is mainly composed of the following modules: project management module, problem analysis module, innovative technique module, knowledge base module, and solution management module.

The innovative design process of the PSS based on TRIZ and function incentives can be realized through the PSS design module of CAIP 3.0. PSS design module mainly includes demand analysis, function modeling, function incentives, and solution generation. The PSS function blueprint construction was implemented by the function modeling submodule in CAIP 3.0. The interaction of product functions and service functions was implemented by the function incentives submodule in CAIP 3.0. The design solutions generation and evaluation were realized through solution generation submodule according to the existing knowledge base of CAIP 3.0. In CAIP 3.0, designers first input product/service functions and function attributes. After clicking the "finish button," a PSS function blueprint is generated automatically. The PSS function modeling is finally realized. According to different evolution routes, different function incentive strategies were carried out on the PSS function blueprint. Finally, the PSS innovation design solutions were generated using the existing knowledge base of CAIP 3.0.

\section{Agricultural Machinery PSS Innovation Design}

China is a large agricultural country with 900 million farmers. It is currently transitioning from traditional agriculture into modern agriculture. The demand for agricultural machinery products is large, and agricultural machinery production accounts for a large proportion of China's manufacturing industry. Traditional agricultural machinery manufacturers had no other way to increase their profits except for profiting from selling machinery and providing simple maintenance service. However, farmers often only use single functions offered by traditional agricultural machines, and they do not receive professional training in farming. In the face of different crops and fertility levels, farmers can rely on their own experiences to cultivate. Moreover, agricultural machinery manufacturers urgently need agricultural machinery with innovative PSS design. With the transformation to the PSS, agricultural machinery manufacturers can abandon the traditional manufacturing model. Traditional agricultural machinery enterprises transformed into agricultural service enterprises by providing crop growth management and training. The proposed PSS design method in this study was verified through the agricultural machinery.

5.1. Agricultural Machinery Demand Analysis. First, the PSS design needed to acquire and analyze customers' demand and to obtain original customers' demand data (most of the data in this study came from the Internet) which were obtained by means of customer interviews and market feedback. These data were input into the demand analysis 
submodule. At present, customers want agricultural machinery to offer multifunctional efficiency, high reliability, good operability, beautiful appearance, energy-saving features, and environmental protection. The preprocessing algorithm of customers' requirements in the submodule was used to classify and combine the original customers' requirements. The sorted customers' needs were classified according to basic needs, existing needs, expected needs, and irrelevant needs. Then, the analytic hierarchy process was used to rank the priority weight among the classified customers' needs. Figure 4 shows the analysis submodule of customers' demands on agricultural machinery.

\subsection{Agricultural Machinery Function Model Construction.} On the basis of existing agricultural machinery, the corresponding function model was constructed. Product functions were divided into product use functions and product management functions, whereas service functions were divided into visible service functions and the invisible service functions. Functions obtained by customers directly through agricultural machinery products were defined as product use functions. Examples of such functions are cultivating land, sowing seeds, irrigating crops, spraying pesticides, removing weeds, applying chemical fertilizer, and harvesting crops. Functions obtained by customers through software technology and manufacturer interactive access were defined as product management functions. These functions include remote monitoring, automatic positioning, sensing information, uploading data, and managing data. Functions obtained by customers through direct experience were defined as visible service functions, which include product trial, periodic maintenance, training, fault diagnosis, maintenance products, and recycling of waste products. Functions that cannot be directly perceived by customers through the thirdparty service provider were defined as invisible service functions, such as risk aversion, soil analysis, and fertilizer production and transportation. Figure 5 shows the function model construction of the agricultural machinery PSS based on CAIP 3.0.

\subsection{Evolutionary Road Selection and Function Incentives.} After function input, the PSS function blueprint was generated automatically using CAIP 3.0. The relationship between service function and product function was represented, and the function correlation matrix of the agricultural machinery was established. According to the function incentive strategies corresponding to different evolutionary routes, the functions of other regions in the PSS blueprint were selected and integrated. Figure 6 shows the function incentive selection of the agricultural machinery.

According to the following evolution routes, different function incentive strategies were adopted to the agricultural machinery PSS innovation design.

5.3.1. Evolutionary Road 1: Increase the Useful Function of the Existing Product. The corresponding function incentive strategy was synergetic innovation. The "fault diagnosis" function of the visual service functions and the "remote monitoring" function of the product use functions complemented each other. The operating condition information collected by traditional agricultural machinery was used for troubleshooting only when a problem occurred. Nonetheless, the preventive inspection and maintenance of the agricultural machinery could be done on the basis of these data. According to big data analysis technology, remote technical maintenance guidance and fault warning could be provided to farmers. The failure rate of the agricultural machinery and possible losses caused by defects were significantly reduced.

5.3.2. Evolution Road 2: Lower the Cost. The corresponding function incentive strategy was supplement innovation. The "soil professional analysis" function of the invisible service functions and the "data management" function of the product management functions collaborated with each other. The agricultural production information was collected to understand the impact of soil condition on crop yield, and the collected data were stored in the service database. The scanned land morphology was divided into small pieces, and the soil information of each small piece was collected and analyzed through the sensor installed on the agricultural machinery. The data on the impact of soil conditions on crop yield were stored in the database and analyzed. Optimal seed ratio, optimal fertilization scheme, optimal use of the pesticides with minimal environmental pollution, and most reasonable irrigation methods were determined, to provide a reference for farmers.

\subsubsection{Evolution Road 3: Reduce Environmental} Consumption. The corresponding function incentive strategy was substitution innovation. The "fertilize" function of the product use functions was replaced by the "fertilizer transport" function of the invisible service functions. Fertilizer was applied to the roots of the crops through the buried fertilization system. Chemical fertilizer producers established alliances with agricultural machinery manufacturers to obtain first-hand information about customers and their soils. According to the data, fertilizer producers provided a customer with a complete analysis of soils and crops. They can also provide customers with complete crop fertilization solutions including optimal ratio of required fertilizer, schedule of crop fertilization, and customized fertilizers for different crops. The fertilizer producers charged according to the area (square kilometers) that received fertilization services.

\subsection{Function Solving and Conceptual Solution Evaluation.} The preventive maintenance system of the agricultural machinery product was obtained by "supplement innovation." With the help of specialized knowledge and professional service, useful functions increased and the 


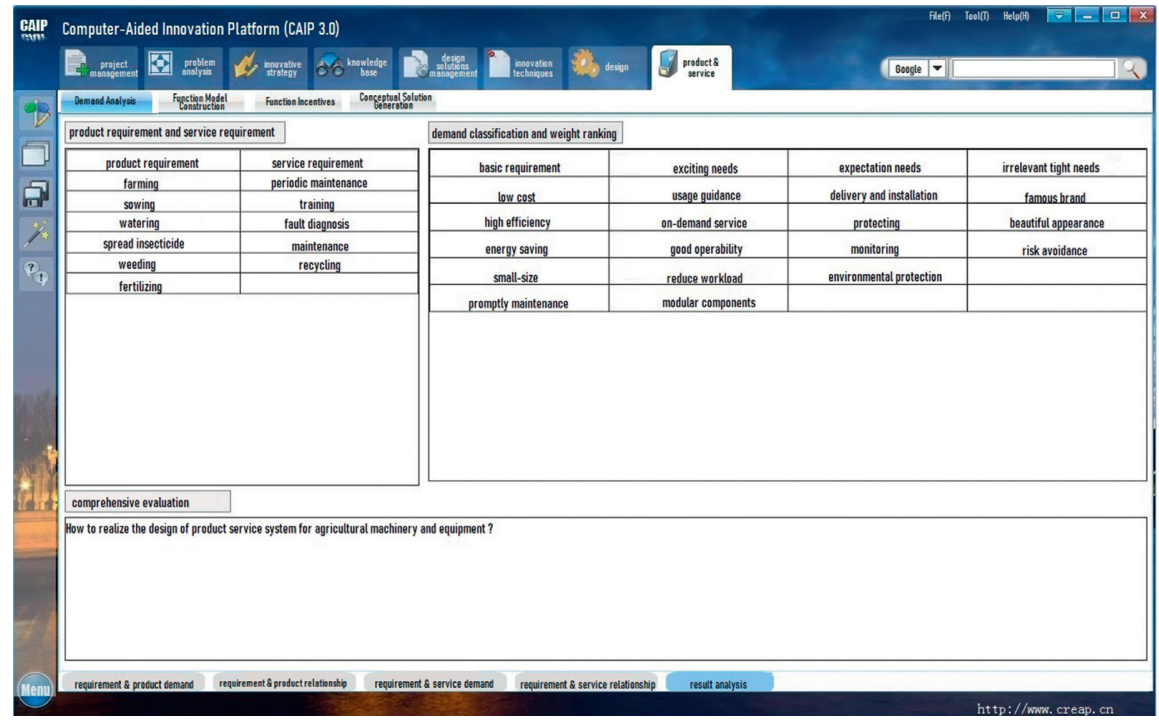

FIgUre 4: Analysis submodule of customers' demand of agricultural machinery based on CAIP 3.0.

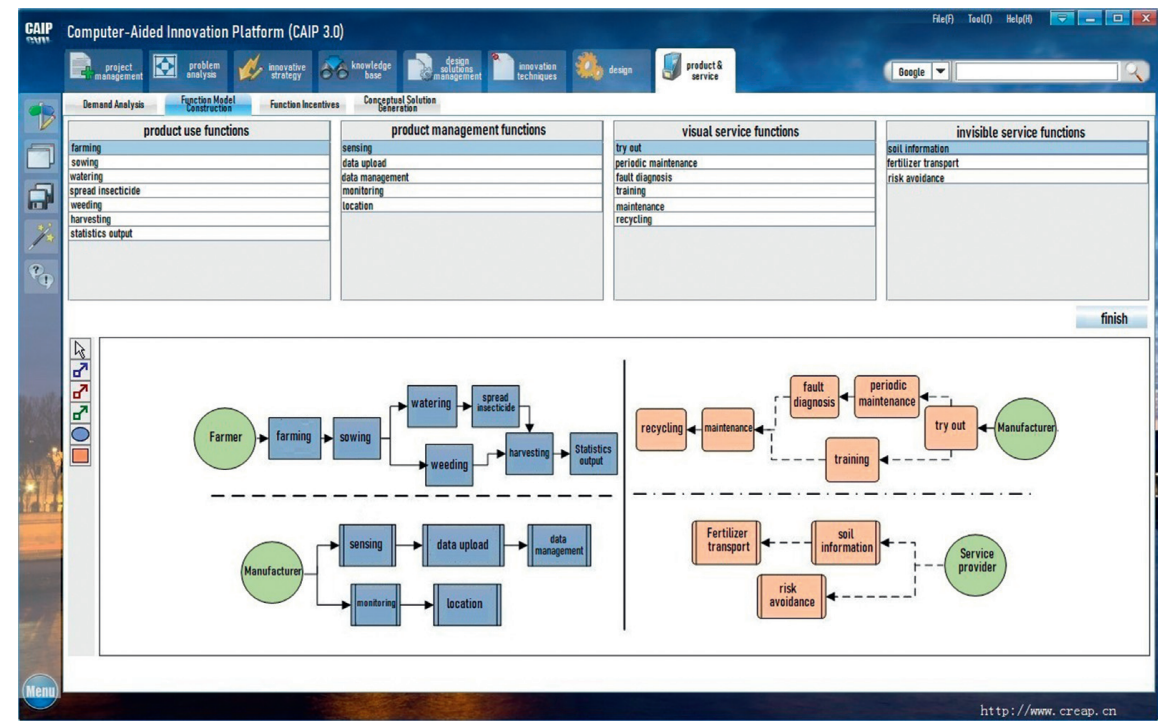

FIGURE 5: Function blueprint submodule of the agricultural machinery PSS based on CAIP 3.0.

value of the product was optimized. The crop growth management service system was obtained through "synergistic innovation." The output of crops on the land was maximized, and the cost was reduced as much as possible. The buried fertilization system was obtained through "substitution innovation." A complete crop fertilization scheme was provided to farmers directly, and the fertilizer plant charged per service. To gain more innovative solutions, the knowledge base was established to seek appropriate engineering examples. The original solutions were solved by function to principle mapping. Finally, the detailed design was carried out. The designer evaluated the new PSS solutions according to the potential market feasibility cost and the actual situation of the enterprise. The optimal PSS solution was determined by using the existing search algorithms, as shown in Figure 7.

\section{Discussion of Results}

6.1. Novelty and Advantages. The distinctive feature of TRIZ is systematic problem solving process. The whole problemsolving process was guided by TRIZ tools, which indicate the direction of the problem solving. Substantial research has been conducted on PSS design based on TRIZ [12, 28, 29], which adopted different tools in problem definition, problem solving, and solution evaluation stages. Existing studies mainly focused on the application of conflict matrix to define a problem and to solve the problem through innovation principle, separation principle, and standard solution. In this study, on the basis of the ideal solution method of TRIZ, the evolutionary route of the PSS innovation design was explored according to the proportion of products and services and the change of product ownership. In the conceptual design stage, the blindness caused by design can be 


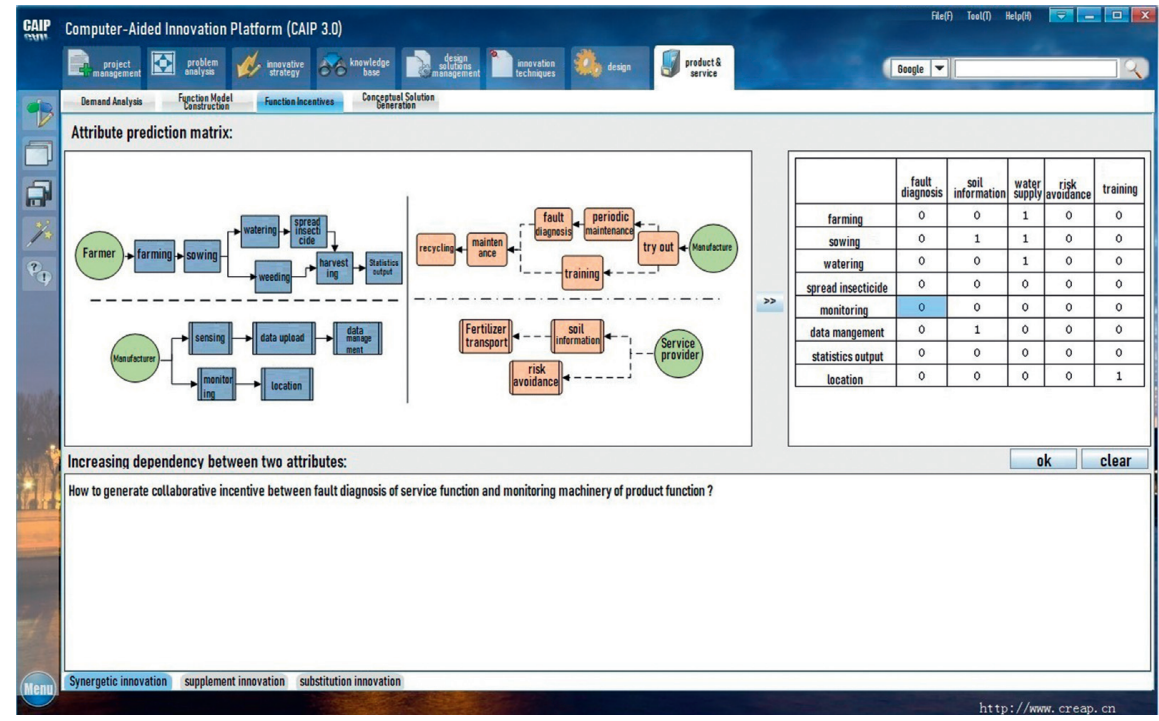

FIGURE 6: Function incentive selection submodule of the agricultural machinery PSS based on CAIP 3.0.

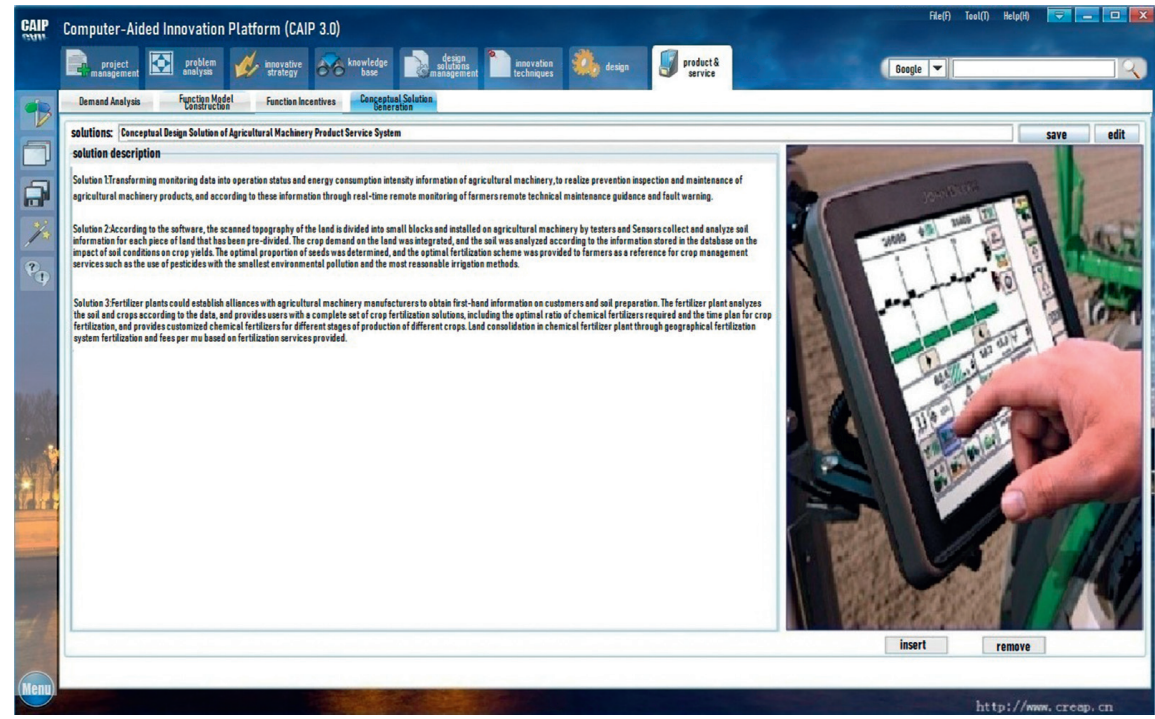

FIGURE 7: Design solutions submodule of the agricultural machinery PSS based on CAIP 3.0.

effectively improved by looking for the optimal integration method of product function and service function at different stages.

This study also constructed computer-aided PSS innovation design modules using CAIP 3.0. By building a function model, evolution route selection, incentive function and solving, and concept scheme evaluation, it provided a useful tool for designers in the conceptual design and scheme design stages. Moreover, it promoted designers' creativity in the creative design phase. CAIP 3.0 system was applied in an agricultural machinery manufacturing enterprise to guide designers in an enterprise to design differentiated products by combining services and to improve the product competitiveness of the enterprise.
6.2. Managerial Implications. This study introduced services in the concept design stage to reduce production costs and to increase the value of physical products. Reducing service costs was easier than reducing production costs. By reducing service costs and improving service quality, the market competitiveness of enterprises can be improved.

Under fierce market competition, products that cannot meet the market demand will be eliminated, and a differentiated design that comes only from a physical product cannot adapt in the market. Therefore, this study built differentiated products with services through product and service function interaction to improve the quality and adaptability of external services, to expand the scope of services, and ultimately to gain benefits. 
With the growing environmental problems, the environmental protection requirements of enterprises are becoming increasingly high. Servicization of manufacturing enterprises is an alternative under environmental pressure. It can reduce the negative impact of tangible products on the environment by selling services instead of products.

6.3. Limitations. Despite these innovations, the present study has limitations. First, the cognitive mechanism of the conceptual solutions generated by the designer in the PSS concept design process and the cognitive basis of the service participants' behavior were not considered. Nevertheless, product designers' cognitive behavior can be used to produce comparable and commensurable results when analyzed by PSS designers. In addition, the PSS concept design lacked quantitative methods to select and evaluate the design solutions. The demands of users, manufacturers, service providers, and other stakeholders needed to be integrated, and a quantitative evaluation mechanism needed to be set to select and evaluate the PSS conceptual design from multiple perspectives. These two points above will be the authors' future research directions.

\section{Conclusions}

In this study, a PSS innovation design method based on IFR of TRIZ and function incentive strategy was proposed. In this innovation mode, three possible evolution routes of the PSS were proposed. The function model of the PSS was established by the PSS function blueprint and system function diagram. On the basis of the evolution routes, different function incentive strategies were carried out to obtain the conceptual design solutions. The best PSS solution was generated by using the existing knowledge base and search algorithm. The relationship between product and service was analyzed and clarified in the conceptual design stage. Material flow (the quantity of the product) was reduced, and environmental friendliness was increased through this method. Finally, the PSS design process of agricultural machinery based on CAIP 3.0 was analyzed as an example to verify this method.

\section{Data Availability}

The data can be found in http://www.creap.cn/

\section{Conflicts of Interest}

The authors declare that there are no conflicts of interest regarding the publication of this paper.

\section{References}

[1] E. Manzini, C. Vezzoli, and G. Clark, "Product-service systems: using an existing concept as a new approach to sustainability," Journal of Design Research, vol. 1, no. 2, pp. 27-40, 2001.

[2] H. Meier, O. Völker, and B. Funke, "Industrial productservice systems (IPS2)," The International Journal of Advanced
Manufacturing Technology, vol. 52, no. 9-12, pp. 1175-1191, 2011.

[3] T. Hara, T. Arai, and Y. Shimomura, "A CAD system for service innovation: integrated representation of function, service activity, and product behaviour," Journal of Engineering Design, vol. 20, no. 4, pp. 367-388, 2009.

[4] S. Jiang, D. Feng, C. Lu et al., "Research on the construction of the spiral evolutionary design methodology for a product service system based on existing products," in Proceedings of the Institution of Mechanical Engineers, Part B: Journal of Engineering Manufacturevol. 234, no. 4, pp. 825-839, 2020.

[5] W. Li and F.-T. Chan, "Multi-objective configuration optimization for product-extension service," Journal of Manufacturing Systems, vol. 37, pp. 113-125, 2015.

[6] D. Yin, X. Ming, Z. Liu, and X. Zhang, "A fuzzy ANP-QFD methodology for determining stakeholders in product-service systems development from ecosystem perspective," Sustainability, vol. 12, no. 8, 2020.

[7] M. Sholihah, Y. Mitake, T. Nakada et al., "Innovative design method for a valuable product-service system: concretizing multi-stakeholder requirements," Journal of Advanced Mechanical Design, Systems, and Manufacturing, vol. 13, no. 5, 2019.

[8] T. Sakao and Y. Shimomura, "Service engineering: a novel engineering discipline for producers to increase value combining service and product," Journal of Cleaner Production, vol. 15, no. 6, pp. 590-604, 2007.

[9] G. Pezzotta, F. Pirola, R. Pinto, and F. Akasaka, "A Service Engineering framework to design and assess an integrated product-service," Mechatronics, vol. 31, pp. 169-179, 2015.

[10] N. Shimomura and M. Fargnoli, "Designing product-service systems: a review towards a unified approach," in Proceedings of the International Conference On Industrial Engineering And Operations Management, pp. 817-837, Rabat, Morocco, April 2017.

[11] G.-S. Altshuller, The Innovation Algorithm: TRIZ, Systematic Innovation and Technical Creativity, Technical Innovation Center, Inc., Shanghai, China, 1999.

[12] S. Kim and B. Yoon, "Developing a process of concept generation for new product-service systems: a QFD and TRIZ-based approach," Service Business, vol. 6, no. 3, pp. 323-348, 2012.

[13] C.-H. Lee, C.-H. Chen, and Y.-C. Lee, "Customer requirement-driven design method and computer-aided design system for supporting service innovation conceptualization handling," Advanced Engineering Informatics, vol. 45, p. $101117,2020$.

[14] J.-W. Wang and J.-M. Zhang, "Research on innovative design and evaluation of agricultural machinery products," Mathematical Problems in Engineering, vol. 2019, Article ID 8179851, 18 pages, 2019.

[15] Y.-H. Wang, C.-H. Lee, and A. J. C. Trappey, "Service design blueprint approach incorporating TRIZ and service QFD for a meal ordering system: a case study," Computers \& Industrial Engineering, vol. 107, pp. 388-400, 2017.

[16] W. Song and T. Sakao, "A customization-oriented framework for design of sustainable product/service system," Journal of Cleaner Production, vol. 140, pp. 1672-1685, 2017.

[17] L. Yang and K. Xing, "Innovative conceptual design approach for product service system based on TRIZ," in Proceedings of the 2013 10th International Conference on Service Systems and Service Management, pp. 247-252, IEEE, Hong Kong, China, July 2013. 
[18] J. L. Chen and Y. Liu, "Innovative design and assessment of low-carbon emission concept product service systems," The Philosopher's Stone For Sustainability, pp. 369-374, Springer, Berlin, Germany, 2013.

[19] N. Haber, M. Fargnoli, and T. Sakao, "Integrating QFD for product-service systems with the Kano Model and fuzzy AHP," Total Quality Management and Business Excellence, vol. 31, pp. 1-26, 2018.

[20] N. Haber, M. Fargnoli, and T. Sakao, "PSS modularization: a customer-driven integrated approach," International Journal of Production Research, vol. 57, pp. 1-17, 2018.

[21] N. Haber and M. Fargnoli, "A practical ANP-QFD methodology for dealing with requirements' inner dependency in PSS development," Computers \& Industrial Engineering, vol. 127, pp. 536-548, 2019.

[22] T. Sakao, W.-Y. Song, and J. Matschewsky, "Creating service modules for customising product/service systems by extending DSM," CIRP Annals-Manufacturing Technology, vol. 66, pp. 21-24, 2017.

[23] J. Lee and M. Abuali, "Innovative Product Advanced Service Systems (I-PASS): methodology, tools, and applications for dominant service design," The International Journal of Advanced Manufacturing Technology, vol. 52, no. 9-12, pp. 1161-1173, 2011.

[24] H. Son, Y. Kwon, S.-C. Park et al., "Using a design structure matrix to support technology road mapping for productservice systems," Technology Analysis \& Strategic Management, vol. 20, no. 3, pp. 223-250, 2018.

[25] Y. Umeda, M. Ishii, M. Yoshioka, and T. Tomiyama, "Supporting conceptual design based on the function-behaviorstate modeler," Artificial Intelligence for Engineering Design, Analysis and Manufacturing, vol. 10, no. 4, pp. 275-288, 1996.

[26] G.-L. Shimomura, "How to design a service," European Journal Of Marketing, vol. 16, 1982.

[27] K.-N. Otto, Product Design: Techniques In Reverse Engineering And New Product Development, Tsinghua University Press, Beijing, China, 2003.

[28] J. P. Dlego-Augusto, T. C. Carla-Schwengber, J. CarlosFernando et al., "State of the art on the role of the theory of inventive problem solving in sustainable product-service systems: past, present, and future," Journal of Cleaner Production, vol. 212, pp. 489-504, 2019.

[29] L.-J. Yang and K. Xing, "Innovative conceptual design approach for product service system based on TRIZ," in Proceedings of the International Conference on Service Systems \& Service Management, IEEE, Hong Kong, China, July 2013. 